\title{
Nutritional management of Crohn's disease
}

\author{
Clare F. Donnellan, Lee H. Yann and Simon Lal
}

\begin{abstract}
Nutritional care and therapy forms an integral part of the management of patients with Crohn's disease (CD). Nutritional deficiencies result from reduced oral intake, malabsorption, medication side effects and systemic inflammation due to active disease. Enteral nutrition has a role in support for the malnourished patient, as well as in primary therapy to induce and maintain remission. The use of parenteral nutrition in CD is mainly limited to the preoperative setting or for patients with intestinal failure, but does not offer any additional advantage over EN in disease control. Dietary modifications, including eliminationreintroduction diets and a low fermentable, oligosaccharides, disaccharides, monosaccharides and polyols (FODMAP) diet may improve symptoms but there are currently no data to suggest that these approaches have any role in the induction or maintenance of remission.
\end{abstract}

Keywords: Crohn's disease, enteral nutrition, intestinal failure, micronutrient deficiency, parenteral nutrition, protein energy malnutrition

\section{Introduction}

Crohn's disease (CD) is a chronic, relapsing, inflammatory disease, associated with malnutrition in $20-85 \%$ of patients [Goh and O'Morain, 2003], particularly, but not confined to, those with small bowel disease. Factors that compromise protein energy nutrition in CD include poor oral intake, malabsorption from active disease or following surgery, hypercatabolism due to active inflammation, and side effects from different treatment strategies. Deficiencies in micronutrients, vitamins and trace elements also occur, with iron deficiency the most common [Gisbert and Gomollon, 2008]. Vitamin D deficiency is also gaining increasing recognition, due to its role in bone health and other diseases [Christakos and DeLuca, 2011]. Recognition and treatment of malnutrition is essential since it is associated with complications, especially postoperative healing and septic complications.

Distinct from treatment of malnutrition is a role for nutrition as a primary therapy in CD. This was initially postulated in adults in 1973, when a small series of patients with $\mathrm{CD}$ treated with an elemental diet were demonstrated to have reduced Crohn's activity, in addition to improved nutrition [Voitk et al. 1973]. Since then, multiple trials and meta-analyses have attempted to assess the anti-inflammatory impact of enteral feed.
This review discusses common macro- and micronutrient deficiencies, the role for oral, enteral nutrition (EN) and parenteral nutrition (PN) and the evidence supporting nutrition as a primary therapy in CD.

\section{Protein energy malnutrition}

It is difficult to accurately establish the rate of malnutrition in CD due to widely differing definitions. Rates as variable as $20-85 \%$ have been published [Han et al. 1999; Harries and Rhodes, 1985; Gassull et al. 1986; Cabre and Gassull, 2001; Dieleman and Heizer, 1998], but these should be seen in the context of the prevalence of malnutrition in general acute inpatients of 34\% [Russell and Elia, 2011]. In addition, a growing proportion of newly diagnosed patients are obese, reflecting the rise in obesity in the general population [Gerasimidis, 2011]. The largest published series by Nguyen and Munsell of 36,448 American inpatients with $\mathrm{CD}$ only detected a malnutrition rate of $6.1 \%$; however, these data were based on ICD codes and therefore may be an underrepresentation [Nguyen and Munsell, 2008]. Nevertheless, the authors identified clear risk factors for malnutrition, such as fistulizing disease (odds ratio (OR) 1.65, 95\% confidence interval (CI) 1.50-1.82) and bowel surgery (OR 1.37, 95\% CI 1.27-1.48) [Nguyen and Munsell, 2008]. Notably,
Ther Adv Gastroenterol

(2013) 6(3) 231-242

DOI: $10.1177 /$

$1756283 \times 13477715$

(c) The Author(s), 2013. Reprints and permissions: http://www.sagepub.co.uk/ journalsPermissions.nav

Correspondence to: Clare F. Donnellan BSc, MBBS, MRCP, MD Consultant

Gastroenterologist, Leeds Gastroenterology Institute, Bexley Wing, Level 4, St James's University Hospital, Leeds LS9 7JT. UK clare.donnellanaleedsth. nhs.uk

Lee H. Yann MBChB, FRACP

Department of Gastroenterology, North Shore Hospital, Takapuna, Auckland, New Zealand

Simon Lal BSc, MBChB, FRCP, PhD

Intestinal Failure Unit, Salford Royal NHS

Foundation Trust, UK 
malnutrition was associated with an increased risk of in-hospital mortality (OR 3.49, 95\% CI 2.89-4.23) and increased length of stay (11.9 versus 5.8 days, $p<0.00001)$ [Nguyen and Munsell, 2008].

As no single measure predicts overall nutritional status in patients with CD, a multidimensional approach has been proposed to include measurement of body composition, dietary intake, biochemical measures and muscle strength [Geerling et al. 1998]. However, this is clearly not practical for all patients in routine clinical practice and therefore the use of nutritional screening tools, such as the Malnutrition Universal Screening Tool (MUST) [Elia, 2003], which incorporates important measures such as body mass index [Mijac et al. 2010] should be applied to the general $\mathrm{CD}$ population to identify patients at risk of malnutrition. Selected patients should then undergo more detailed assessment, including dietary intake, anthropometric evaluation and measurement of vitamins and trace elements.

\section{Vitamin, macronutrient and micronutrient deficiency}

Micronutrients refer to trace minerals and vitamins required in minute quantities, as opposed to macronutrients, required in larger amounts (fats, carbohydrates, proteins, calcium, phosphate and magnesium etc). Inadequate oral intake of dietary vitamins and micronutrients is prevalent in patients with CD [Rigaud et al. 1994; Pons et al. 2009; Gerasimidis, 2011]. Factors that contribute to decreased food intake, independently of disease activity, include loss of appetite, hunger and depressed mood [Rigaud et al. 1994]. An analysis of the 7-day dietary pattern of 74 patients with CD showed failure to meet recommended daily dietary intake of all nutrients, except vitamin B12, despite adequate protein/energy intake and a normal body mass index. This was particularly so with intake of vitamins $\mathrm{A}, \mathrm{C}$ and $\mathrm{E}$, folate, calcium and zinc, with prevalence rates of each deficiency exceeding $40 \%$. These findings were independent of disease activity, although the study was not powered to assess this as a primary outcome [Aghdassi et al. 2007].

Consequences of micronutrient deficiencies range from overt clinical syndromes, including anaemia (due to deficiencies in iron, B12 and folate), osteomalacia (vitamin D), peripheral neuropathy (vitamin $\mathrm{E}$ ), night blindness (vitamin $\mathrm{A}$ ), beriberi (thiamine) and stomatitis or glossitis (vitamin B groups). In many cases, however, patients with micronutrient deficiencies present with nonspecific symptoms such as fatigue and depression.

Iron deficiency anaemia is the most common 'extra-intestinal' manifestation of inflammatory bowel disease (IBD), with prevalence rates ranging from $36 \%$ to $88 \%$ [Gisbert and Gomollon, 2008; Gerasimidis, 2011]. In a study evaluating the practice of iron replacement in patients with IBD in Europe, only 18-30\% of 1173 patients with CD with iron deficiency anaemia received iron intravenously [Stein et al. 2011], whereas international guidelines [Gasche et al. 2007] advocate that the intravenous, rather than oral, may be the preferred route of iron administration. However, a prospective multicentre trial of 100 patients with CD or ulcerative colitis (UC) with iron deficiency demonstrated an improvement in iron levels and quality of life regardless of the route of administration [Gisbert et al. 2009]. Of the 78 patients with a haemoglobin between 10 and $12 \mathrm{~g} / \mathrm{dl}$ (women) or between 10 and $13 \mathrm{~g} / \mathrm{dl}$ (men) treated with oral iron, only 5\% developed intolerance, necessitating a switch to the parenteral route. An explanation for the strikingly high rate of tolerance of oral iron in this study may be the relatively low dose used (equating to approximately $100 \mathrm{mg}$ elemental iron). Indeed, when choosing the dose of oral iron to administer, it is important to recognize that a maximum amount of 10-20 mg can be absorbed from the gastrointestinal tract (proximal small bowel) [Rimon et al. 2005].

Vitamin B12 deficiency occurs in approximately one-fifth of patients with CD [Yakut et al. 2010; Headstrom et al. 2008], although this will clearly be higher in patients with loss of absorptive terminal ileal surface due to disease activity or after surgical resection. Although deficiency is thought to occur in all patients after resection of more than $60 \mathrm{~cm}$ of terminal ileum [Mowat et al. 2011], a small study of 42 patients with resections of between 20 and $60 \mathrm{~cm}$ demonstrated abnormal B12 absorption in 52\%, highlighting the need to monitor these patients carefully [Duerksen et al. 2006]. Recent British Society of Gastroenterology guidelines suggest giving B12 replacement in all patients with ileal resections greater than $20 \mathrm{~cm}$ and yearly B12 measurements if less than $20 \mathrm{~cm}$ [Mowat et al. 2011].

Low serum and red cell folate levels have been reported in up to $28 \%$ of patients, particularly in those with active disease [Elsbourg and Larsen, 
1979; Hoffbrand et al. 1968], though more recent studies using modern laboratory techniques put this much lower at $4.3 \%$ [Oldenburg et al. 2000]. In addition to poor intake and malabsorption, folate deficiency can also result from competitive inhibition from sulphasalazine use. There is a concern that folate deficiency may be associated with colorectal cancer in patients with UC or colonic CD, possibly secondary hyperhomocysteinaemia, which leads to DNA methylation and DNA instability [Phelip et al. 2008]. Observational studies suggest that folate supplementation may be associated with reduced colorectal neoplasia in IBD [Lashner et al. 1997], and the recently published British Society of Gastroenterology guidelines [Cairns et al. 2010] note that folate supplementation may be beneficial, especially in patients who may have folate deficiency due to sulphasalazine therapy, although these guidelines acknowledge that data supporting this statement are relatively sparse.

Malabsorption rather than dietary insufficiency is the likely main underlying mechanism leading to fat-soluble vitamin deficiencies [Kuwabara et al. 2009] which, in turn, can be associated with metabolic bone disorders [Kuwabara et al. 2009]. Vitamin D deficiency can, of course, result in osteomalacia. Studies of bone mineral density in patients with $\mathrm{CD}$ demonstrate variable rates of osteopaenia and osteoporosis, due to the definitions used, but all show significant reduction in bone health with osteopaenia rates of $23-77 \%$ [Abitbol et al. 1995; Bjarnason et al. 1997; Pigot et al. 1992] and osteoporosis rates of $17-30.6 \%$ [Bjarnason et al. 1997; Compston et al. 1987]. As stated, vitamin deficiencies, including vitamin $\mathrm{K}$, are associated with reduced bone density, and other risk factors in IBD include corticosteroid use [Dear et al. 2001], jejunal involvement or bowel resection [Robinson et al. 1998], stricturing or penetrating disease [Cravo et al. 2010], and ongoing inflammation [Paganelli et al. 2007]. Vertebral fractures (often asymptomatic) have been demonstrated in $20-22 \%$ of patients with CD, including those under 30 years old [Klaus et al. 2002]. The exact pathogenesis is unclear but interesting data from 26 patients with $C D$ in remission suggest suppressed bone formation with normal bone resorption, which may provide therapeutic avenues in the future [Schoon et al. 2001].

Depletion of vitamin A stores can occur in patients with CD in the absence of any clinical manifestations of this vitamin deficiency, such as night blindness [Bousvaros et al. 1998]. As vitamin A is stored entirely in the liver, serum vitamin $\mathrm{A}$ is a poor marker of body reserves [Rumi et al. 2000], thus making detection of deficiency difficult. Patients with primary sclerosing cholangitis are particularly at risk of deficiencies in vitamin A and other fat-soluble vitamins due to chronic cholestasis [Jorgensen et al. 1995]. However, deficiency of vitamin $\mathrm{E}$ leading to peripheral neuropathy is a rare clinical occurrence [Bousvaros et al. 1998].

\section{Role of diet and Crohn's development}

There have been several attempts to use epidemiological data to link dietary factors to onset of CD. A meta-analysis suggested a positive association between high intake of fat, polyunsaturated fatty acids, $\omega 6$ fatty acids and meat with risk of developing $C D$, while higher fruit and fibre intakes appeared to be protective [Hou et al. 2011]. However, data are very heterogeneous with predominantly retrospective dietary histories, so it is difficult to clarify the strength of any association.

\section{Nutrition support}

\section{Oral nutritional supplementation}

For patients with $\mathrm{CD}$ who are malnourished, or at risk of malnutrition, oral nutritional supplements (ONS) can be well tolerated, allowing individuals to meet their nutritional requirements with resultant improvements in anthropometry [Harries et al. 1983]. European Society for Clinical Nutrition and Metabolism (ESPEN) guidelines recommend up to $600 \mathrm{kcal} /$ day in the form of ONS, suggesting this to be beneficial [Lochs et al. 2006].

\section{Enteral tube feeding for nutritional support}

If daily nutritional requirements are not adequately met by oral intake, alternative routes such as enteral tube feeding can be used in patients to achieve target intake. In a group of growth-retarded adolescents with $\mathrm{CD}$, nocturnal tube feeding of 1-1.5 liters of non-elemental feed improved weight gain and growth [Aiges et al. 1989]. Continuous feeds are preferred to bolus regimes due to the reduced risk of complications [Lochs et al. 2006]. For patients requiring long-term enteral tube feeding, gastrostomy insertion is well tolerated in children and adults with CD [Anstee and Forbes, 2000; Cosgrove and Jenkins, 1997]. 


\section{Parenteral nutrition}

There is no evidence that PN provides any benefit over EN as primary therapy for CD (or UC). $\mathrm{PN}$ is only indicated for nutritional support in patients with CD if nutrition cannot be optimized using oral or enteral routes alone. Examples may include intestinal failure (IF) due to short bowel syndrome resulting from multiple previous bowel resections or associated with high output stomas or fistulas. It is important that most patients should be allowed to continue oral intake if possible, despite the use of PN. In practice a mixture of oral, enteral and parenteral routes may be used together to achieve the best nutritional status [Woodcock et al. 2001].

\section{Preoperative parenteral nutrition}

PN may be used to improve nutritional status prior to bowel surgery to improve postoperative outcomes in the malnourished patient when the oral or enteral route cannot be used [Van Gossum et al. 2009]. ESPEN guidelines do not give any other specific guidance for the perioperative patient with CD, except to state use of PN should be considered as for any surgical patient [Van Gossum et al. 2009].

\section{Postoperative parenteral nutrition}

Postoperative $\mathrm{PN}$ is principally required for patients who develop IF, defined as 'obstruction, dysmotility, surgical resection, congenital defect or disease associated loss of absorption, characterised by the inability to maintain protein energy, fluid, electrolyte or micronutrient balance' [O'Keefe et al. 2006].

IF has been classified into three types [Lal et al. 2006]. Type 1 IF is transient and occurs in patients who develop a postoperative ileus and may require short-term intravenous nutrition, although this is often not needed. Type $2 \mathrm{IF}$ describes patients with complex disease, often with septic, metabolic and nutritional complications, for which a multidisciplinary approach is essential, using the 'SNAP' algorithm (treat Sepsis, support Nutrition, demonstrate Anatomy and Plan future management) [Lal et al. 2006]. These patients may require long periods of $\mathrm{PN}$, often in specialist centres or at home. Type 3 IF includes patients with more stable disease on long-term home PN, who may be candidates for intestinal transplantation.

\section{Enteral nutrition as primary therapy}

There is evidence to suggest that EN can induce and maintain remission in children and adults with CD [Zachos et al. 2007] but not with UC [Lochs et al. 2006]. Though corticosteroids are often used in adults to induce remission, it is important to recognize that these medications carry significant risks and do not necessarily lead to mucosal healing [Rutgeerts, 2001]. EN is often used as first-line therapy to induce remission in children [Lochs et al. 2006], not least because this approach is associated with growth and minimal side effects compared with steroids [Belli et al. 1988] and may be associated with mucosal healing [Borrelli et al. 2006], although this has not been confirmed [Afzal, 2004]. By contrast, EN may be underused as a primary therapeutic option in adults, partly due to compliance issues.

\section{Induction of remission: enteral nutrition}

Initial data suggesting a role for EN came from a small uncontrolled study of 13 patients who received an elemental diet to improve nutritional status prior to surgery [Voitk et al. 1973]. While weight gain and improved nutrition parameters were observed, there also appeared to be an antiinflammatory effect. A further small series of patients with protein-calorie malnutrition due to extensive small bowel Crohn's demonstrated similar results with reduced protein and lymphocyte loss from the gut [Logan et al. 1981].

Since then, there have been multiple trials and meta-analyses evaluating the role of $\mathrm{EN}$ as primary therapy in CD, but often with small numbers and heterogenous groups of patients. With these caveats in mind, the most recent meta-analysis has demonstrated a significant benefit of steroids over $\mathrm{EN}$ for inducing remission in $\mathrm{CD}$ ( $\mathrm{OR}$ $0.36,95 \%$ CI $0.23-0.56$, with number needed to treat of 4) [Zachos et al. 2007]. When only data for 'higher quality' studies were assessed (based on randomization, blinding and description of withdrawals and dropouts), there was no significant difference between steroids and EN. However, this finding should be interpreted with caution due to the low numbers of patients and the heterogenous nature of the studies included. Indeed, EN should be considered in appropriate patients. The challenge, however, is to know who these are: there are no trials comparing EN versus placebo; it is unclear how long exclusive EN is needed; and data are very heterogeneous with regards to response related to disease distribution 
[Wilschanski et al. 1996; Afzal, 2009, Buchanan et al. 2009, Rubio et al. 2011].

$\mathrm{EN}$ as primary therapy has been evaluated in various formulations, including elemental and polymeric feeds. Elemental feeds consist of nutrition in its simplest form, for example, single amino acids, as opposed to oligopeptide 'semi-elemental' or full protein polymeric feeds. Elemental feeds were originally designed by the National Aeronautics and Space Administration (NASA) as easily digestible, water-soluble foods that produced smaller faecal bulk when consumed in space [Winitz et al. 1965]. There is clear evidence that elemental feeds have a primary anti-inflammatory effect in CD, with evidence of improved intestinal permeability [Teahon et al. 1991], reduced inflammatory cytokine production [Yamamoto et al. 2005; Sanderson and Croft, 2005] and mucosal healing [Yamamoto et al. 2005], although only when given exclusively [Johnson, 2006]. Various theories have been proposed as to how these benefits are rendered [O'Sullivan and O'Morain, 1998], but a definitive answer is lacking. The most popular theory was that elemental diets had a reduced antigenic load to the inflamed bowel compared with full protein feeds [O'Sullivan and O'Morain, 1998]. However, this may not be the case because polymeric feeds have since been found to be equally efficacious [Zachos et al. 2007; Grogan et al. 2012]. In addition, because polymeric feeds are more palatable than elemental feeds, the former tend to be used first line. It has been further suggested that the anti-inflammatory properties of enteral feeds relate to their fat content, with emerging evidence that lower fat feeds are more efficacious [Gassull et al. 2002]. Indeed modification of various dietary components, such as reducing long-chain triglyceride content [Zachos et al. 2007] or enrichment with fish oils [MacLean et al. 2005] have been evaluated but studies are small and results equivocal. For example, subgroup analysis in a Cochrane review of six studies did not demonstrate a statistically significant difference in remission rates between low and high long-chain triglyceride feeding formulae (OR 1.39, 95\% CI 0.78-2.48) [Zachos et al. 2007].

Enrichment of enteral feeding with transforming growth factor $\beta$, a key regulatory peptide in immunoregulation, is a promising new development. Supported by evidence of efficacy from the paediatric literature [Rubio et al. 2011], there has only been one fully published trial in adult patients with CD [Triantafillidis et al. 2006]. In an uncontrolled observational study of patients with active CD given 4 weeks of exclusive Modulen IBD (Nestlé, Lausanne, Switzerland), 11 out of 29 patients were in remission [as defined by Crohn's Disease Activity Index $(\mathrm{CDAI})<150$ ] and a further 8 had a response (CDAI drop $>50$ ) [Triantafillidis et al. 2006]. Larger, randomized, controlled trials are clearly needed to verify these data.

In summary, EN can play a role in inducing remission in adult patients with $\mathrm{CD}$, but further work is needed not just to define the phenotype of patients likely to respond, the duration of treatment required and the most beneficial formulae, but also to evaluate the putative mechanism by which EN modifies the inflammatory response. In addition, there is marked variation in use of EN between paediatric and adult gastroenterologists in the UK, reflected in the recent National Institute for Health and Clinical Excellence (NICE) guidance [NICE, 2012], and even between paediatric gastroenterologists in Europe and America, the latter with low uptake [Stewart, 2011]. This is unlikely to change without more robust data to support regular use of EN.

\section{Maintenance of remission: enteral nutrition}

While induction of remission can be achieved with EN, use of exclusive EN for longer term disease maintenance is more challenging due to compliance issues.

Uncontrolled, prospective data have suggested maintenance of CD can be prolonged by the addition of EN to an unrestricted normal diet [Koga et al. 1993; Verma et al. 2000]. These lent support to previous retrospective data in children and adolescents, demonstrating prolonged remission (and also improved growth) if patients received nocturnal nasogastric feeding [Wilschanski et al. 1996].

There have only been two randomized controlled trials assessing EN as maintenance therapy in CD [Verma et al. 2001; Takagi et al. 2006]. The first of these [Verma et al. 2001] gave 33 patients with steroid-dependent CD (two failed attempts to wean steroids) either an elemental or a polymeric diet to make up $30-50 \%$ of their requirements. Response was defined as successful withdrawal of steroids without a CDAI increase of more than 100 points to a score greater than 200 and avoidance of surgery; this was achieved in 14 of the 27 patients who tolerated the feed. Subsequently an 
open-label extension allowed the 14 'responders' to choose whether or not to remain on enteral supplements. Of the seven patients who chose to return to an unrestricted diet, all relapsed within 4 months, requiring further steroids, whereas six of the seven patients who continued on enteral supplements remained in remission at 24 months.

The second paper by Tagaki and colleagues randomized a group of 51 patients with CD in remission to receive either a 'free diet' or half elemental diet [Takagi et al. 2006]. At 2 years, relapse rates were lower for those receiving enteral feed (hazard ratio $0.40,95 \%$ CI $0.16-0.98$ ) after multivariate adjustment for age, sex, disease duration, disease site and mean baseline CDAI.

As with induction of remission, identification of factors that predict which patients will respond would facilitate a targeted approach. A retrospective study of 145 patients in remission, with twothirds receiving maintenance $\mathrm{EN}$, identified penetrating CD (RR 3.89; 95\% CI 1.58-9.62), colonic involvement (RR 3.10; 95\% CI 1.396.90) and previous history of surgery (RR 2.48; 95\% CI 1.16-5.33) to be factors that predicted recurrence [Esaki et al. 2006]. Recurrence rates were high (42/98 EN group versus 29/47 normal $\operatorname{diet;} p=0.047$ ), and it is difficult to assess the applicability of these data since remission was induced with PN and the only other therapy used was 5-aminosalicylic acid drugs.

While there are no studies comparing EN with immunomodulators for CD maintenance, one study has looked at the effect of using EN as an adjunct to biological therapy. EN provided at approximately half of the daily energy requirement over 56 weeks, in addition to infliximab maintenance therapy, did not alter clinical remission rates [Yamamoto et al. 2010], which may not be an unexpected finding given that EN tends to be used in relatively mild disease [Lochs et al. 2006], whereas infliximab is used in patients with $\mathrm{CD}$ at higher risk of relapse.

Postoperative recurrence rates of $\mathrm{CD}$ are high, with symptomatic recurrence rates of $20 \%$ and endoscopic recurrence rates of $73 \%$ of patients within 1 year following surgery [Rutgeerts et al. 1990]. A prospective, non-randomized trial studied recurrence in 40 patients with CD after either ileal or ileocolonic resection, using EN (versus normal diet) for disease maintenance [Yamamoto et al. 2006]. Maintenance of EN over 12 months was associated with reduced clinical ( $5 \%$ versus $35 \%, p=0.048)$ and endoscopic (30\% versus $70 \%, p=0.027)$ recurrence compared with the non-EN group. Notably, all 20 patients with EN completed this study, which represents an unusually low dropout rate, likely reflecting patient selection preoperatively.

Concerns have also arisen as to whether longterm EN for CD maintenance may impair quality of life because of the restrictive nature of the dietary intervention or the need for repeated nasogastric tube intubations. Tagaki and colleagues found no difference in quality of life (as measured by the short IBD questionnaire) in patients maintained on EN versus those that continued a normal diet [Takagi et al. 2009]. Furthermore, multivariate analysis demonstrated EN to be independently associated with improvement of health-related quality of life in patients with $\mathrm{CD}$ with disease duration of over 10 years [Kuriyama et al. 2009].

\section{Maintenance of remission: dietary modification}

A variety of dietary modifications and measures have been evaluated in maintaining CD remission. For example, fish oils, which are a major source of $\omega 3$ fatty acids, have been shown to have specific anti-inflammatory properties in a variety of diseases [Wall et al. 2010]. However, a Cochrane review of six trials failed to demonstrate a clear clinical benefit of using fish oils in CD maintenance [Turner, 2009]. Though pooled results from all studies favoured the use of $\omega 3$ fatty acids (RR 0.77, 95\% CI 0.61-0.98, $p=0.03$ ), a combination of all studies showed statistically significant heterogeneity. In addition, due to a large dropout rate, 'estimated' rates of relapse were calculated, which were nonsignificant (RR $0.59,95 \%$ CI 0.34-1.03, $p=0.06$ ). Furthermore, combined results from the two largest and rigorous trials, EPIC-1 and EPIC-2, reported in the same manuscript [Feagan et al. 2008], failed to reach statistical significance (RR 0.88, 95\% CI 0.74-1.05).

An 'elimination-reintroduction' diet was one of the earliest described modification diets evaluated for disease maintenance in CD. 'Elimination' involves remission induced by elemental feeds, followed by careful and slow 'reintroduction' of single food types to enable identification of those that precipitate symptoms. Evidence of efficacy of this approach derives from a trial of 93 patients who, after achieving remission with elemental 
feed, were randomly assigned to either receive tapering steroids over 3 months with standard dietary advice or to reintroduction of a single food type per day, excluding those that induced symptoms [Riordan et al. 1993]. Relapse rates (as defined by Harvey-Bradshaw Index scores greater than 6) were high in both groups at 2 years, but were significantly better in the reintroduction group $(62 \%$ versus $79 \%, p=0.048)$. However, the latter group needed 12 visits to dieticians during the 2 year period, which has service cost implications. An alternative is the low-fibre, fat-limited exclusion (LOFFLEX) reintroduction diet, [Woolner et al. 1998] which involves a faster reintroduction phase of varied food types, instead of single food types, after EN-induced remission. The LOFFLEX approach was developed after observations that a patient with CD often developed symptoms after ingestion of foods that were high in fibre and fat. In an open-label study of this approach, in which patients chose which diet to use, 2-year remission rates for 76 patients were noninferior to a single-food type reintroduction diet (56\% versus $59 \%)$, but with good compliance rates $(8.3 \%$ noncompliant with LOFFLEX versus $14.3 \%$ with single-food type reintroduction) [Woolner et al. 1998].

An alternative dietary modification known as the 'FODMAP' (fermentable, oligo-, di-, monosaccharides and polyols) diet has also been evaluated in CD. Examples of FODMAP-containing foods include fructose (apples, pears, corn syrup), lactose (dairy products, soft cheeses), fructans and galactans (wheat, cabbage, broccoli, watermelon) and polyols (apples, apricots, cauliflower, sorbitol). Symptoms were assessed in 52 patients with $\mathrm{CD}$ at 3-6 months after initiation of FODMAP restriction, with an improvement in 56\% [Gearry et al. 2009]. Though this was a retrospective questionnaire-based study, trials comparing a lowFODMAP diet with a control group or other diets have not yet been published. Furthermore, FODMAP diets are relatively restrictive, so concerns have been raised about nutrient deficiencies associated with these diets.

It is unclear whether dietary exclusion-reintroduction diets or FODMAP diets maintain remission through persistence of mucosal healing or are of predominant symptomatic benefit by alleviating 'functional' symptoms. FODMAP diets have been shown to be efficacious in patients with irritable bowel syndrome [Staudacher et al. 2011], and it is likely that they also reduce functional symptoms in patients with $\mathrm{CD}$, possibly by reducing the osmotic load and bacterial fermentation associated with the food delivered [Gibson and Shepherd, 2010], rather than having a primary anti-inflammatory effect.

\section{Conclusion}

Nutritional deficiencies in patients with $\mathrm{CD}$ are common. It is important that use of malnutrition screening tools, such as MUST [Elia, 2003] is embedded into routine practice. In addition, there should be a low threshold to investigate for specific micronutrient deficiencies, particularly common abnormalities such as iron deficiency anaemia. IBD standards state all patients should have access to dieticians, both for nutritional support and consideration of primary therapy [IBD Standards Group, 2009]. Although the first IBD audit demonstrated low rates of uptake, more recent data suggest this has improved, at least when considering availability of dietitians, which is reported to be in $97 \%$ of hospital sites taking part in the audit [Royal College of Physicians, 2011].

Nutritional support should be provided by oral or enteral means wherever possible, reserving $\mathrm{PN}$ for patients with intestinal failure and, in rare cases, for perioperative optimization when oral nutrition or EN is unsuccessful.

For primary therapy, EN should be considered in patients with mild to moderate $\mathrm{CD}$ to induce remission. Polymeric diets are better tolerated than and as equally efficacious as elemental feeds, but the role of enriched feeds needs further clarification. Other unanswered questions are the optimal duration of exclusive EN and the phenotype of disease that will derive most benefit. Nevertheless, EN can be a very useful treatment in motivated patients. In addition, using EN as a third to half of diet appears to prolong maintenance of $C D$, although data are few. There is no role for PN to either induce or maintain remission.

Finally current dietary modifications do not provide any prognostic benefit but may be of value in addressing symptom control.

\section{Funding}

This research received no specific grant from any funding agency in the public, commercial, or notfor-profit sectors. 


\section{Conflict of interest statement}

The authors declare no conflicts of interest in preparing this article.

\section{References}

Abitbol, V., Roux, C., Chaussade, S., Guillemant, S., Kolta, S., Dougados, M. et al. (1995) Metabolic bone assessment in patients with inflammatory bowel disease. Gastroenterology 108: 417-422.

Afzal, N., Davies, S., Paintin, M., ArnaudBattandier, F., Walker-Smith, J., Murch, S. et al. (2009) The use of exclusive enteral nutrition for induction of remission in children with Crohn's disease demonstrates that disease phenotype does not influence clinical remission. Aliment Pharmacol Ther 30: $501-507$

Afzal, N., Van der Zaag-Loonen, H., ArnaudBattandier, F., Davies, S., Murch, S., Derkx, B. et al. (2004) Improvement in quality of life of children with acute Crohn's disease does not parallel mucosal healing after treatment with exclusive enteral nutrition. Aliment Pharmacol Ther 20: 167-172

Aghdassi, E., Wendland, B., Stapleton, M., Raman, M. and Allard, J. (2007) Adequacy of nutritional intake in a Canadian population of patients with Crohn's disease. F Am Diet Assoc 107: 1575-1580.

Aiges, H., Markowitz, J., Rosa, J. and Daum, F. (1989) Home nocturnal supplemental nasogastric feedings in growth-retarded adolescents with Crohn's disease. Gastroenterology 97: 905-910.

Anstee, Q. and Forbes, A. (2000) The safe use of percutaneous gastrostomy for enteral nutrition in patients with Crohn's disease. Eur $\mathcal{F}$ Gastroenterol Hepatol 12: 1089-1093.

Belli, D., Seidman, E., Bouthillier, L., Weber, A., Roy, C., Pletincx, M. et al. (1988) Chronic intermittent elemental diet improves growth failure in children with Crohn's disease. Gastroenterology 94: 603-610.

Bjarnason, I., Macpherson, A. and Mackintosh, C. (1997) Reduced bone density in patients with inflammatory bowel disease Gut 40: 228-233.

Borrelli, O., Cordischi, L., Cirulli, M., Paganelli, M., Labalestra, V., Uccini, S. et al. (2006) Polymeric diet alone versus corticosteroids in the treatment of active pediatric Crohn's disease: a randomized controlled open-label trial. Clin Gastroenterol Hepatol 4: 744-753.

Bousvaros, A., Zurakowski, D., Duggan, C., Law, T., Rifai, N., Goldberg, N. et al. (1998) Vitamins $\mathrm{A}$ and $\mathrm{E}$ serum levels in children and young adults with inflammatory bowel disease: effect of disease activity. 7 Pediatr Gastroenterol Nutr 26: 129-135.

Buchanan, E., Gaunt, W., Cardigan, T., Garrick, V., McGrogan, P. and Russell, R. (2009) The use of exclusive enteral nutrition for induction of remission in children with Crohn's disease demonstrates that disease phenotype does not influence clinical remission. Alim Phar Ther 30: 501-507.

Cabre, E. and Gassull, M. (2001) Nutrition in inflammatory bowel disease: impact on disease and therapy. Curr Opin Gastroenterol 17: 342-349.

Cairns, S., Scholefield, J., Steele, R., Dunlop, M., Thomas, H., Evans, G. et al. (2010) Guidelines for colorectal cancer screening and surveillance in moderate and high risk groups (update from 2002). Gut 59: 666-689.

Christakos, S. and DeLuca, H. (2011) Minireview: vitamin D: is there a role in extraskeletal health? Endocrinology 152: 2930-2936.

Compston, J., Judd, D., Crawley, E., Evans, W., Evans, C., Church, H. et al. (1987) Osteoporosis in patients with inflammatory bowel disease. Gut 28: 410-415.

Cosgrove, M. and Jenkins, H. (1997) Experience of percutaneous endoscopic gastrostomy in children with Crohn's disease. Arch Dis Child 76: 141-143.

Cravo, M., Guerreiro, C., dos Santos, P., Brito, M., Ferreira, P., Fidalgo, C. et al. (2010) Risk factors for metabolic bone disease in Crohn's disease patients. Inflamm Bowel Dis 16: 2117-2124.

Dear, K., Compston, J. and Hunter, J. (2001) Treatments for Crohn's disease that minimise steroid doses are associated with a reduced risk of osteoporosis. Clin Nutr 20: 541-546.

Dieleman, L. and Heizer, W. (1998). Nutritional issues in inflammatory bowel disease. Gastroenterol Clin North Am 27: 435-451.

Duerksen, D., Fallows, G. and Bernstein, C. (2006). Vitamin B12 malabsorption in patients with limited ileal resection. Nutrition 22: 1210-1213.

Elia, M. (2003) Screening for Malnutrition: $A$ Multidisciplinary Responsibility. Development and Use of the Malnutrition Universal Screening Tool (MUST) for Adults. Malnutrition Advisory Group (MAG), BAPEN.

Elsborg, L. and Larsen, L. (1979) Folate deficiency in chronic inflammatory bowel diseases. Scand $\mathcal{F}$ Gastroenterol 14: 1019-1024.

Esaki, M., Matsumoto, T., Nakamura, S., Yada, S., Fujisawa, K., Jo, Y. et al. (2006) Factors affecting recurrence in patients with Crohn's disease under nutritional therapy. Dis Colon Rectum 49: S68-S74. 
Feagan, B., Sandborn, W., Mittmann, U., Bar-meir, S., D'Haens, G., Bradette, M. et al. (2008) Omega-3 free fatty acids for the maintenance of remission in Crohn disease: the EPIC randomized controlled trials. FAMA 299: 1690-1697.

Gasche, C., Berstad, A., Befrits, R., Beglinger, C., Dignass, A., Erichsen, K. et al. (2007) Guidelines on the diagnosis and management of iron deficiency and anemia in inflammatory bowel diseases. Inflamm Bowel Dis 13: 1545-1553.

Gassull, M., Abad, A., Cabré, E., González-Huix, F., Giné, J. and Dolz, C. (1986) Enteral nutrition in inflammatory bowel disease. Gut 27: 76-80.

Gassull, M., Fernández-Bañares, F., Cabré, E., Papo, M., Giaffer, M., Sánchez-Lombraña, J. et al. (2002) Fat composition may be a clue to explain the primary therapeutic effect of enteral nutrition in Crohn's disease: results of a double blind randomised multicentre European trial. Gut 51: 164-168.

Gearry, R., Irving, P., Barrett, J., Nathan, D., Shepherd, S. and Gibson, P. (2009) Reduction of dietary poorly absorbed short-chain carbohydrates (FODMAPs) improves abdominal symptoms in patients with inflammatory bowel disease a pilot study. F Crohns Colitis 3: 8-14.

Geerling, B., Badart-Smook, A., Stockbrügger, R. and Brummer, R. (1998) Comprehensive nutritional status in patients with long-standing Crohn disease currently in remission. Am F Clin Nutr 67: 919-926.

Gerasimidis, K., McGrogan, P. and Edwards, C. (2011) The aetiology and impact of malnutrition in paediatric Crohn's disease. F Hum Nut Diet 24: 313-26.

Gibson, P. and Shepherd, S. (2010) Evidence-based dietary management of functional gastrointestinal symptoms: the FODMAP approach. $\mathcal{f}$ Gastroenterol Hepatol 25: 252-258.

Gisbert, J., Bermejo, F., Pajares, R., Pérez-Calle, J., Rodríguez, M., Algaba, A. et al. (2009) Oral and intravenous iron treatment in inflammatory bowel disease: hematological response and quality of life improvement. Inflamm Bowel Dis 15: 1485-1491.

Gisbert, J. and Gomollon, F. (2008) Common misconceptions in the diagnosis and management of anemia in inflammatory bowel disease. $A m \mathcal{F}$ Gastroenterol 103: 1299-1307.

Goh, J. and O'Morain, C. (2003) Review article: nutrition and adult inflammatory bowel disease. Aliment Pharmacol Ther 17: 207-320.

Grogan, J., Casson, D., Terry, A., Burdge, G., El-Matary, W. and Dalzell, A. (2012) Enteral feeding therapy for newly diagnosed pediatric Crohn's disease: a double blind randomized controlled trial with two years follow up. Inflamm Bowel Dis 18: 246-253.
Han, P., Burke, A., Baldassano, R., Rombeau, J. and Lichtenstein, G. (1999) Nutrition and inflammatory bowel disease. Gastroenterol Clin North Am 28: 423-443.

Harries, A., Jones, L., Danis, V., Fifield, R., Heatley, R., Newcombe, R. et al. (1983) Controlled trial of supplemented oral nutrition in Crohn's disease. Lancet 1: 887-890.

Harries, A. and Rhodes, J. (1985). Undernutrition in Crohn's disease: an anthropometric assessment. Clin Nutr 4: 87-89.

Headstrom, P., Rulyak, S. and Lee, S. (2008) Prevalence of and risk factors for vitamin B12 deficiency in patients with Crohn's disease. Inflamm Bowel Dis 14: 217-223.

Hoffbrand, A., Stewart, J., Booth, C. and Mollin, D. (1968) Folate deficiency in Crohn's disease: incidence, pathogenesis, and treatment. $\mathrm{Br}$ Med f 2: 71-75.

Hou, J., Abraham, B. and El-Serag, H. (2011) Dietary intake and risk of developing inflammatory bowel disease: a systematic review of the literature. $\mathrm{Am} \mathcal{F}$ Gastroenterol 106: 563-573.

IBD Standards Group (2009) Quality Care: Service Standards for the Healthcare of People Who Have Inflammatory Bowel Disease (IBD). Available at: http:// www.ibdstandards.org.uk/ibd-standards.asp (accessed 23 January 2013).

Johnson, T., MacDonald, S., Hill, S., Thomas, A. and Murphy, M. (2006) Treatment of active Crohn's disease in children using partial enteral nutrition with liquid formula: a randomised controlled trial. Gut 55: 356-361

Jorgensen, R., Lindor, K., Sartin, J., LaRusso, N. and Wiesner, R. (1995) Serum lipid and fat-soluble vitamin levels in primary sclerosing cholangitis. $\mathcal{F}$ Clin Gastroenterol 20: 215-219.

Klaus, J., Armbrecht, G., Steinkamp, M., Brückel, J., Rieber, A., Adler, G. et al. (2002) High prevalence of osteoporotic vertebral fractures in patients with Crohn's disease. Gut 51: 654-658.

Koga, H., Iida, M., Aoyagi, K., Matsui, T. and Fujishima, M. (1993) Long-term efficacy of low residue diet for the maintenance of remission in patients with Crohn's disease. Nihon Shokakibyo Gakkai Zasshi 90: 2882-2888.

Kuriyama, M., Kato, J. and Morimoto, N. (2009) Enteral nutrition improves health-related quality of life in Crohn's disease patients with long disease duration. Hepatogastroenterology 56: 321-327.

Kuwabara, A., Tanaka, K., Tsugawa, N., Nakase, H., Tsuji, H., Shide, K. et al. (2009) High prevalence of vitamin $\mathrm{K}$ and $\mathrm{D}$ deficiency and 
decreased BMD in inflammatory bowel disease. Osteoporos Int 20: 935-942.

Lal, S., Teubner, A. and Shaffer, J. (2006). Review article: intestinal failure. Aliment Pharmacol Ther 24: 19-31.

Lashner, B., Provencher, K., Seidner, D., Knesebeck, A. and Brzezinski, A. (1997) The effect of folic acid supplementation on the risk for cancer or dysplasia in ulcerative colitis. Gastroenterology 112: 29-32.

Lochs, H., Dejong, C., Hammarqvist, F., Hebuterne, X., Leon-Sanz, M., Schütz, T. et al. (2006) ESPEN guidelines on enteral nutrition: gastroenterology. Clin Nutr 25: 260-274.

Logan, R., Gillon, J., Ferrington, C. and Ferguson, A. (1981) Reduction of gastrointestinal protein loss by elemental diet in Crohn's disease of the small bowel. Gut 22: 383-387.

MacLean, C., Mojica, W., Newberry, S., Pencharz, J., Garland, R., Tu, W. et al. (2005) Systematic review of the effects of n-3 fatty acids in inflammatory bowel disease. Am F Clin Nutr 82: 611-619.

Mijac, D., Jankovic, G., Jorga, J. and Krstic, M. (2010). Nutritional status in patients with active inflammatory bowel disease: prevalence of malnutrition and methods for routine nutritional assessment. Eur F Int Med 21: 315-319.

Mowat, C., Cole, A., Windsor, A., Ahmad, T., Arnott, I., Driscoll, R. et al. (2011) Guidelines for the management of inflammatory bowel disease in adults. Gut 60: 571-607.

NICE (2012) Crohn's Disease - Management in children, adults and young people NCG152. Available at: http://www.nice.org.uk/nicemedia/ live/13936/61001/61001.pdf

Nguyen, G. and Munsell, M. (2008) Nationwide prevalence and prognostic significance of clinically diagnosable protein-calorie malnutrition in hospitalized inflammatory bowel disease patients. Inflamm Bowel Dis 14: 1105-1111.

O’Keefe, S., Buchman, A., Fishbein, T., Jeejeebhoy, K., Jeppesen, P. and Shaffer, J. (2006) Short bowel syndrome and intestinal failure: consensus definitions and overview. Clin Gastroenterol Hepatol 4: 6-10.

Oldenburg, B., Fijnheer, R., van der Griend, R., vanBerge-Henegouwen, G. and Koningsberger, J. (2000) Homocysteine in inflammatory bowel disease: a risk factor for thromboembolic complications? $A m \mathcal{F}$ Gastroenterol 95: 2825-2830.

O'Sullivan, M. and O'Morain, C. (1998) Nutritional therapy in Crohn's disease. Inflamm Bowel Dis 4: 45-53.

Paganelli, M., Albanese, C., Borrelli, O., Civitelli, F., Canitano, N., Viola, F. et al. (2007) Inflammation is the main determinant of low bone mineral density in pediatric inflammatory bowel disease. Inflamm Bowel Dis 13: 416-423.

Phelip, J., Ducros, V., Faucheron, J., Flourie, B. and Roblin, X. (2008) Association of hyperhomocysteinemia and folate deficiency with colon tumors in patients with inflammatory bowel disease. Inflamm Bowel Dis 14: 242-248.

Pigot, F., Roux, C., Chaussade, S., Hardelin, D., Pelleter, O., Du Puy Montbrun, T. et al (1992) Low bone mineral density in patients with inflammatory bowel disease. Dig Dis Sci 37: 1396-1403.

Pons, R., Whitten, K., Woodhead, H., Leach, S., Lemberg, D. and Day, A. (2009) Dietary intakes of children with Crohn's disease. Br F Nutr 102: 1052-1057.

Rigaud, D., Angel, L., Cerf, M., Carduner, M., Melchior, J., Sautier, C. et al. (1994) Mechanisms of decreased food intake during weight loss in adult Crohn's disease patients without obvious malabsorption. Am f Clin Nutr 60: 775-781.

Rimon, E., Kagansky, N., Kagansky, M., Mechnick, L., Mashiah, T., Namir, M. et al. (2005) Are we giving too much iron? Low-dose iron therapy is effective in octogenarians. $A m \mathcal{F} \mathrm{Med} 118$ : 1142-1147.

Riordan, A., Hunter, J., Cowan, R., Crampton, J., Davidson, A., Dickinson, R. et al. (1993) Treatment of active Crohn's disease by exclusion diet: East Anglian multicentre controlled trial. Lancet 342: 1131-1134.

Robinson, R., al-Azzawi, F., Iqbal, S., Kryswcki, T., Almond, L., Abrams, K. et al. (1998) Osteoporosis and determinants of bone density in patients with Crohn's disease. Dig Dis Sci 43: 2500-2506.

Royal College of Physicians (2011) UK Inflammatory Bowel Disease Audit 3rd Round. Available at: http:// www.rcplondon.ac.uk/sites/default/files/report-of-theresults-for-the-national-organisational-audit-of-adultinflammatory-bowel-disease-services-in-the-uk-2011. pdf (accessed 23 January 2013).

Rubio, A., Pigneur, B., Garnier-Lengline, H., Talbotec, C., Schmitz, J., Canioni, D. et al. (2011) The efficacy of exclusive nutrition therapy in paediatric Crohn's disease, comparing fractionated oral vs. continuous enteral feeding. Alim Pharm Ther 33: 1332-1339.

Rumi, G. Jr, Szabó, I., Vincze, A., Matus, Z., Tóth, G. and Mózsik, G. (2000) Decrease of serum carotenoids in Crohn's disease. F Physiol Paris 94: 159-161.

Russell, C. and Elia, M. (2011) Nutrition Screening Survey in the UK and Republic of Ireland in 2010. Report, BAPEN, UK, February. 
Rutgeerts, P. (2001). Review article: the limitations of corticosteroid therapy in Crohn's disease. Aliment Pharmacol Ther 15: 1515-1525.

Rutgeerts, P., Geboes, K., Vantrappen, G., Beyls, J., Kerremans, R. and Hiele, M. (1990) Predictability of post operative course of Crohn's disease. Gastroenterology 99: 956-963.

Sanderson, I. and Croft, N. (2005). The antiinflammatory effects of enteral nutrition. $\mathcal{F}$ Parenter Enteral Nutr 29(4 Suppl.): S134-S138.

Schoon, E., Geerling, B., Van Dooren, I., Schurgers, L., Vermeer, C., Brummer, R. et al. (2001) Abnormal bone turnover in long-standing Crohn's disease in remission. Aliment Pharm Ther 15: 783-792.

Staudacher, H., Whelan, K., Irving, P. and Lomer, M. (2011) Comparison of symptom response following advice for a diet low in fermentable carbohydrates (FODMAPs) versus standard dietary advice in patients with irritable bowel syndrome. $\mathcal{F}$ Hum Nutr Diet 24: 487-495.

Stein, J., Bager, P., Befrits, R., Danese, S., Gasche, C., Magro, F. et al. (2011) Current European practice in diagnosis and treatment of IBD-associated anaemia. 7 Crohns Colitis 5: S45.

Stewart, M. (2011) Physician Attitudes and Practices of Enteral Nutrition as Primary Treatment of Paediatric Crohn's Disease in North America. F Pediatr Gastroenterol Nutr 52: 38-42.

Takagi, S., Utsunomiya, K., Kuriyama, S., Yokoyama, H., Takahashi, S., Iwabuchi, M. et al. (2006) Effectiveness of an 'half elemental diet' as maintenance therapy for Crohn's disease: a randomized-controlled trial. Aliment Pharmacol Ther 24: 1333-1340.

Takagi, S., Utsunomiya, K., Kuriyama, S., Yokoyama, H., Takahashi, S., Umemura, K. et al. (2009) Quality of life of patients and medical cost of "half elemental diet" as maintenance therapy for Crohn's disease: Secondary outcomes of a randomised controlled trial. Dig Liver Dis 41: 390-394.

Teahon, K., Smethurst, P., Pearson, M., Levi, A. and Bjarnason, I. (1991) The effect of elemental diet on intestinal permeability and inflammation in Crohn's disease. Gastroenterology 101: 84-89.

Triantafillidis, J., Stamataki, A., Gikas, A., Sklavaina, M., Mylonaki, M., Georgopoulos, F. et al. (2006) Beneficial effect of a polymeric feed, rich in TGF- $\beta$, on adult patients with active Crohn's disease: a pilot study. Ann Gastroenterol 19: 77-71.

Turner, D., Zlotkin, S., Shah, P. and Griffiths, A. (2009) Omega 3 fatty acids (fish oil) for maintenance of remission in Crohn's disease.
Cochrane Database Syst Rev (1): CD006320.

Available at: http://www.ncbi.nlm.nih.gov/ pubmed/19160277 (accessed January 2012).

Van Gossum, A., Cabre, E., Hebuterne, X., Jeppesen, P., Krznaric, Z., Messing, B. et al. (2009) ESPEN guidelines on parenteral nutrition: gastroenterology. Clin Nutr 28: 415-427.

Verma, S., Holdsworth, C. and Giaffer, M. (2001) Does adjuvant nutritional support diminish steroid dependency in Crohn disease? Scand $\mathcal{F}$ Gastroenterol 36: 383-388.

Verma, S., Kirkwood, B., Brown, S. and Giaffer, M. (2000). Oral nutritional supplementation is effective in the maintenance of remission in Crohn's disease. Dig Liver Dis 32: 769-774.

Voitk, A., Echave, V., Feller, J., Brown, R. and Gurd, F. (1973). Experience with elemental diet in the treatment of inflammatory bowel disease. Is this primary therapy? Arch Surg 107: 329-333.

Wall, R., Ross, R., Fitzgerald, G. and Stanton, C. (2010) Fatty acids from fish: the anti-inflammatory potential of long-chain omega-3 fatty acids. Nutr Rev 68: 280-289.

Wilschanski, M., Sherman, P., Pencharz, P., Davis, L., Corey, M. and Griffiths, A. (1996) Supplementary enteral nutrition maintains remission in paediatric Crohn's disease. Gut 38: 543-548.

Winitz, M., Graff, J., Gallagher, N., Narkin, A. and Seedman, D. (1965) Evaluation of chemical diets as nutrition for man-in-space. Nature 205: 741-743.

Woodcock, N., Zeigler, D., Palmer, M., Buckley, P., Mitchell, C. and MacFie, J. (2001) Enteral versus parenteral nutrition: a pragmatic study. Nutrition 17 : $1-12$.

Woolner, J., Parker, T., Kirby, G. and Hunter, J. (1998) The development and evaluation of a diet for maintaining remission in Crohn's disease. F Hum Nutr Diet 11: 1-11.

Yakut, M., Ustün, Y., Kabaçam, G. and Soykan, I. (2010) Serum vitamin B12 and folate status in patients with inflammatory bowel diseases. Eur $\mathcal{F}$ Intern Med 21: 320-323.

Yamamoto, T., Nakahigashi, M., Umegae, S., Kitagawa, T. and Matsumoto, K. (2005) Impact of elemental diet on mucosal inflammation in patients with active Crohn's disease: cytokine production and endoscopic and histological findings. Inflamm Bowel Dis 11: 580-588.

Yamamoto, T., Nakahigashi, M., Umegae, S., Kitagawa, T. and Matsumoto, K. (2006) Impact 
Visit SAGE journals online http://tag.sagepub.com

(SAGE journals of long-term enteral nutrition on clinical and endoscopic recurrence after resection for Crohn's disease: a prospective, non-randomized, parallel, controlled study. Aliment Pharmacol Ther 25: 67-72.

Yamamoto, T., Nakahigashi, M., Umegae, S. and Matsumoto, K. (2010) Prospective clinical trial: enteral nutrition during maintenance infliximab in Crohn's disease. F Gastroenterol 45: 24-29.

Zachos, M., Tondeur, M. and Griffiths, A. (2007) Enteral nutritional therapy for induction of remission in Crohn's disease. Cochrane Database Syst Rev (1): CD000542. Available at: http://www2.cochrane.org/ reviews/en/ab000542.html (accessed 23 January 2013). 